\title{
How categorization impacts the design of requests: Asking for email addresses in call-centre interactions
}

\author{
M A R I E F L I N F E L D T D, S O P H IE PAR S L OW A N D \\ E L I Z A B E T H S T O K O E \\ Uppsala University, Sweden \\ Loughborough University, UK \\ Loughborough University, UK
}

\section{A B S T R A C T}

\begin{abstract}
Marketing research shows that organizations tailor communication for particular customer 'segments', but little is known about the live design of interaction for different categories. To investigate this, we examine telephone calls to a holiday sales call-centre (for 'seniors') and a university admissions call-centre (for 'young' students). While topically different, call-takers in both datasets requested callers' email addresses in order to progress service. Using conversation analysis, we examine how these requests were designed, where and how 'age' was made relevant, and how subsequent service provision was handled in a way that matched callers' presumed age categories. Contrastive to the static notion of 'segments', we show how recipient design is bound up with categorial considerations while being responsive to the live unfolding of actual interaction. The article demonstrates how a comparative collection-based approach can be used to analyse the relevance of social categories in situations where this is implicit or ambiguous. (Membership categorization, customer segmentation, conversation analysis, recipient design, requests, age)*
\end{abstract}

\section{N T R O D U C T I O N}

How do organizations design communications for targeted groups of recipients as part of providing service? Tailoring messages for particular categories can facilitate various aspects of service provision, but risks being seen as discriminatory if made explicit. The aim of this article is to investigate how an aspect of someone's identity - in this case, their age - may be both explicitly mentioned AND more implicitly oriented to by service providers and users in the systematic design of communicative actions. More specifically, we examine how call-takers design requests for the same information in different ways, thereby exposing presumptions of who their interlocutor is taken to be. This analysis is informed by an investigation of explicit invocations of age and is further supported by examining how service 
users are treated as preferring particular modes of contact for future communications, constructing partitionings that also match their age categories. In contrast to much of the marketing and business literature, in which the process of optimizing customer 'segmentation' methods is often the focus, we thus examine how the live 'segmentation' of service users actually unfolds.

We begin by reviewing the multidisciplinary body of work across communication, marketing, and advertising that deals with the issue of 'segmenting' service users in order to target messages for those groups. We then summarize the basic principles, identified across decades of conversation analytic research, of 'recipient design', that is, how, in social interaction, people build, and sometimes abandon or repair, each turn to take into account the person they are talking to. While a great deal of evidence shows that people design their talk for particular recipients, we focus here on how largely unarticulated categorization of callers underpins the design and sequential organization of requests for their email address.

For example, in the extracts below, two different service providers, in different organizations, are talking to service users. In both cases, the service providers must next elicit the caller's email address to progress the call.

(1) University call

$1 \mathrm{U}$ : And if I can have your email address please.

(2) Holiday sales call

1 S: And uh do you have an email address at all.

Note the similarities in the design of each service provider's turn: both start with a connective and-preface in turn-initial position, 'used to link a question to a preceding question/answer pair' and establish the series of questions as routine (Heritage \& Sorjonen 1994:1). Both are also grammatical yes/no interrogatives (Raymond 2003), to which an email address would constitute a 'preferred' response, in terms of their pragmatic functions. However, while the design of extract (1) assumes that the recipient can easily provide the information requested, extract (2) builds in a contingency that the recipient might not have an email address 'at all'. The recipient in extract (1) is an eighteen-year-old student calling a university. In extract (2), the recipient is a customer of a holiday company that specializes in services for older travelers. However, 'age' is not mentioned in either case. So how can we make the claim that speakers routinely design their requests and other actions on the basis of an identity category such as age?

\section{Audience or customer segmentation and 'personas'}

The topic of 'audience' or 'customer' segmentation and its associated techniques and practices is commonplace in marketing and business fields. The concept of market segmentation was introduced decades ago by Smith (1956:6), as a way of regarding 'a heterogeneous market (one characterized by divergent demand) as a 
number of smaller homogenous markets in response to different product preferences among important market segments'. Segmentation involves partitioning audiences into smaller groups that can be differentially targeted. For instance, organizations might segment customers based on age, gender, location, education, income, 'psychographics' (i.e. personality, lifestyle), or behavioural factors (e.g. Cirksena \& Flora 1995). They can then design products, services, and communications accordingly. Beyond the business sector, segmentation is commonly used in healthcare to tailor messages to key groups and influence behaviour (e.g. Slater 1996).

The rise of 'big' data has enabled complex modelling for customer segmentation, aimed at 'a deeper understanding of customer preferences, needs, and wants by isolating what each segment finds most valuable... [to] more effectively engage with their customers, audience, or users' (An, Kwak, Jung, Salminen, \& Jansen 2018:53). Those involved in user-centred design in technology-based industries create audience segments called 'personas'. Here, data-driven types of user or consumer are developed based on what people already do and what companies know about them from their data trails (e.g. Pruitt \& Adlin 2006). For example, Jansen, Jung, \& Salminen (2019:127) describe how they collect demographic data and information about the content consumed by YouTube users to generate personas and analyse their stability and consistency over time.

The concept of segmentation is not without criticism. While segmentation techniques exist partly to deal with the known heterogeneity of populations, Firat \& Shultz (1997:188) argue that postmodern consumers cannot be segmentedunlike the consumers of the 'modern' era, in which a self-concept that 'suggests a stability in the consumer's orientations and behaviour' underpins a division of people into relatively homogeneous groups. The tropes of postmodernism-the fleeting, multiple, fragmented self - do not lend themselves to the notion of multiple stable market segments from which to develop marketing strategies. Furthermore, critics argue that segmentation reproduces the preferences of dominant cultural groups (e.g. Bedi 2019), and stereotypes and bias can easily backfire on marketers and advertisers. However, while questioning the possibility or value of targeting predefined categories of people, this critique fails to take into account that service or sales situations are ALREADY shaped for particular recipients and that this, in turn, may have less to do with 'segmentation' as marketers define it, and more to do with the way interaction works. That is, if we examine live interaction, we may see how organizations design communication MOMENT-TO-MOMENT for a client or customer who is responding synchronously. In contrast to the inevitably static and stereotypical segments onto which marketers build strategies, interloctors adapt to each other in real time. This may be underpinned by the category memberships, such as age, that they are presumed to occupy IN THAT MOMENT. As McHoul (2007:460) remarks, '[t]his is not "stereotyping" or anything of the sort' but a logical consequence of the way that language provides an indefinite number of ways to describe, reference, and categorize something or someone. We move on 
to review the literature on 'recipient design' and membership categories in the next section.

\section{Conversation analysis, recipient design, and membership categorization}

'Recipient design' is the conversation analytic term for the practices through which talk is designed as a best fit for a respondent. It refers to the 'multitude of respects in which the talk by a party in a conversation is constructed or designed in ways which display an orientation and sensitivity to the... coparticipants' (Sacks, Schegloff, \& Jefferson 1974:727). This involves 'word selection, topic selection, admissibility and ordering of sequences, options and obligations for starting and terminating conversations' (Sacks, Schegloff, \& Jefferson 1974:727). It also includes embodied and prosodic resources, as people 'recipient design greetings on the level of prosody, tailoring them to each addressee and thus hearably displaying a stance toward the current state and character of their social relationship' (Pillet-Shore 2012:375).

A key component of recipient design is how references are made to persons, objects, places, and so on, each requiring speakers to select 'from a variety of lexical and gestural possibilities' (Enfield 2013:433), and 'with an eye to who the recipient is and what the recipient knows about the reference' (Schegloff 1996:459). So, if a speaker says, 'Jane came for dinner', they are treating their recipient as knowing who 'Jane' is. If a speaker knows that their recipient does not know Jane, they might refer to 'Jane from the office', or use a recognizable category in saying that 'a colleague' came for dinner. Not only have conversation analysts shown that speakers design turns for the presumed epistemic status of their recipients (see Heritage 2013), they have also shown how speakers ORIENT to recipient design through mid-utterance repair and reformulation of actions (Goodwin 1979).

Such design attends not only to personalized knowledge about the recipient, but also to their categorial incumbencies, on the basis of which assumptions about what they know or like may be made. While multiple categories are always available to describe a person (someone may at the same time be categorized based on age, occupation, political views, and so on), membership categories are rendered relevant in and through interaction as resources for 'the doing of some activity' (Sacks 1992:597), for example, addressing a recipient or producing an account. To the extent that categories are explicitly mentioned and/or bound to activities or other characteristics, claiming that this category is, indeed, 'relevant' for that particular stretch of interaction can be relatively straightforward (Stokoe 2012). Meanwhile, the conversation analytic focus on privileging participant orientations also 'involves identifying empirical evidence that participants are oriented to [a category] as (potentially) shaping the conduct at hand despite not being explicitly mentioned' (Whitehead 2020:298; cf. Schegloff 2007b). This means that 
conversation analysts should be able to support an analysis of non-verbalized categorial orientations in the recipient design of communicative actions.

As Baker, Emmison, \& Firth (2005:40, emphasis added) note in a study of a technical helpline, call-takers may attend 'to much more than the technical competence of the caller - it includes hearing and responding to "IDENTITY matters"'. In his primer on conversation analysis, Schegloff (2007a:89, emphasis added) also notes that, alongside recipient design considerations for person references and other lexical choices, these also feature in topic selection 'either individually OR CATEGORICALLY'. Nguyen (2011) makes the case that most work to date on recipient design focuses on 'aspects of talk that are designed for the participant(s) in ONE particular conversation', and shows that and how recipient design may be achieved longitudinally, as revealed in an analysis of a pharmacy intern's interactions with patients over time. That is, 'some aspects of recipient design can be carried over to a next interaction', on the basis of which Nguyen argues that the 'recipient' in 'recipient design' 'may be understood as MEMBERS OF THE SAME CATEGORY and not just one particular co-participant in a given conversation' (2011:200).

Where recipients are not explicitly categorized in talk, patterns in routinized conduct may nevertheless provide insight into implicit categorial considerations. As Drew \& Heritage (1992:51) observe, organizations develop practices through which to manage multiple cases of the same type of request or problem 'by assigning them to routine categories'. Stivers \& Majid (2007) show that racial categorizations of the recipient can impact whether they are addressed at all. They investigate categorically different treatment of children in pediatric visits, showing how physicians direct fewer questions to Black children (instead directing them to accompanying parents or carers). Black children are thus treated as unable to answer questions about their own circumstances, indicating an implicit racial and socioeconomic bias in physicians' routinized conduct.

Similarly, recipient categories can have relevance for the information given. In an analysis of calls to a fibromyalgia helpline in the UK, Wilkinson (2011:114) focuses on the use of 'pre-fabricated' talk, which is 'recipient-designed and packaged in a way that displays sensitivity to callers as individuals or as category members', showing how stretches of talk are simultaneously recipient-designed (for callers presumed to know little about fibromyalgia) and also routinized or scripted. In the extract below, Wilkinson notes that such information, here prefaced with the phrase 'a classic example', is delivered routinely to multiple callers.

(3) From Wilkinson (2011:117); Clt: Call-taker, Pen = Penny

112 Clt: hh (.) swollen feelings in the tissues

113 an' a classic example there for a lo:t of

114 women with fibromyalgia is before you

115 develop $^{\circ}$ ed $^{\circ}$ the disease. hh the first thing

116 you did when you got 'ome was kick your

117 shoes off [.hh] after you develop the 
118 Pen: [yes]

119 Clt: disease the first thing you do is take

120 your bra off cause it don't matter what

121 size it is it feels too sma:[11.]

Wilkinson shows that, despite this package of information being delivered to multiple callers, call-takers nevertheless SELECT some but not all callers to use it withgender being the predominant criterium. She observes that cues to gender often are limited just to the voices of the callers: 'a voice that "sounds female" is here TREATED AS RELEVANT by the call-taker when she launches a signature formulation that targets women only' (2011:124; cf. Parslow 2018 on how voice makes old age provisionally available). Crucially, then, Wilkinson claims that a key feature of recipient design that informs the call-taker's selection of this pre-fabricated talk is the recipient's perceived gender. She continues:

\footnotetext{
Analytically, this orientation to gender is identifiable on comparative grounds. However, whereas comparative 'sex differences' research typically starts with the (analytically-defined) categories 'male' and 'female' and looks for differences and similarities across interactions with participants so categorized, this research began by noticing a practice in talk (the signature formulation) and then observed that its production was attentive to the presumed gender of the participants. Gender is thus endogenous to the interaction rather than imposed upon it by the analyst. Moreover, it is (partly) through the call-taker's provision of this gender-specific advice and information that these callers are constituted as women. THE KEY CHALLENGE FOR COMPARATIVE WORK OF THIS TYPE is to specify exactly How an orientation to gender (or some other category set) is consequential for the content and course of the interaction. (Wilkinson 2011:133, emphasis added)
}

In the current article, we approach these issues through a kind of comparative analysis, by examining calls across two datasets, to different organizations, whose 'audiences' are 'segmented' to broadly provide service to 'young' students and 'old' holidaymakers. These categorizations are omnirelevant, at least partly by dint of the phonetic qualities of their voices (see Parslow 2018). By comparing calls to organizations with different caller demographics, we set up the conditions for understanding the possibilities of routinization (saying the same kinds of things to each caller - in this case, requesting the caller's email address) AND recipient design (not all students are young; not all holidaymakers are old). In so doing, we aim to further develop the trajectory of work that brings membership categorization and conversation analysis together (e.g. Stokoe 2012; Whitehead 2020), charting categorial concerns across turn design and sequential organization. We also hope to shed empirical light on the concept of 'segmentation' by considering it as an interactive process.

\section{A T A A N M E THODS}

We analyse data from two UK settings, both of which include a routine actionsoliciting callers' email addresses to progress or confirm service provision. The first dataset comprises thirty calls to the call-centre of a holiday resort company in 2014. These were made available by the company for the purpose of identifying 
practices which could be used for staff training. Much can be gleaned about the 'audience segment' for the company, via their website. Most images are of white, grey-haired people, and the presumed market is connoted through the description of available activities (e.g. '[bowling is] suitable for PEOPLE OF ALL AGES AND ABILITIES - including those who are PARTIALLY SIGHTED or in a WHEELCHAIR'; 'DisABLED parking is also available'; 'We welcome guests who are Blue BADGE HOLDERS to bring their MOBILITY scooters to use during their stay'). Thus, without saying so explicitly, the company's offer is tailored to older customers who may be disabled in an age-relevant way.

The second dataset comprises 200 calls made to a British university admissions office in 2016. These calls happen annually, when students receive their final high school examination results, on which acceptance to a university undergraduate programme is contingent. The call-takers are university representatives and callers' reasons for calling are usually to inquire after a place, having achieved lower than the required grades (see Hoey \& Stokoe 2018). Like the holiday calls, recordings were made available by the university for subsequent training purposes. On the university's website, photographs are more ethnically diverse than the holiday company's but are of visibly young people in a variety of educational, sporting, and social settings. There is also a link to a 'PARENTS' AND CARERS' GUIDE', all of which tacitly segment the intended recipient.

Callers were informed that their calls were being recorded for research and training purposes by automatic call-answering messages. Data have been stored securely under encryption and all extracts have been anonymized. The language of both datasets is almost entirely British English. The analysis has proceeded according to conversation analytic (CA) methods and principles in combination with membership categorization analysis (MCA). $\mathrm{CA}$ is an inductive and predominantly qualitative micro-analytic method for uncovering the tacit, taken-for-granted practices with which participants organize their everyday circumstances (e.g. Hoey \& Kendrick 2018). Sharing the same ethnomethodological foundations as CA, MCA's primary interest is with members' categorial practices (e.g. Sacks 1972; Stokoe 2012).

We started by identifying all instances through which age was made explicitly relevant by participants, thus - in marketing terms - constituting callers as an audience segment. We then collected all cases of call-takers asking callers for their email address. This was one activity that occurred routinely in вотн sets of calls, therefore permitting comparison. While other 'segment'-relevant actions occurred, such as asking about special needs related to disability, these were limited to the holiday dataset. Finally, we analysed subsequently elicited and expressed preferences for how the organization should communicate with the caller (e.g. by email or traditional mail), which often occurred next to requests for email addresses. 
The analysis is presented in three sections: (i) how parties are constituted as members of the relevant audience 'segment', in marketing terms; or how category membership is made relevant to the unfolding interaction, in conversation analytic terms; (ii) how requests for callers' email address are designed and sequentially organized comparatively, across the two datasets; and (iii) how confirmations of service and subsequent communication with the organization are handled.

\section{The relevance of the 'segment'}

We start the analysis with examples of how age is made relevant in the two settings. Extracts (4) and (5) come from the university corpus and show how age (and gender) categories are used to address students in call openings. In extract (4), the student caller $(\mathrm{C})$ has just been transferred from the main contact centre to the relevant department.

(4) (University_173; C: Caller, U: University call-taker)

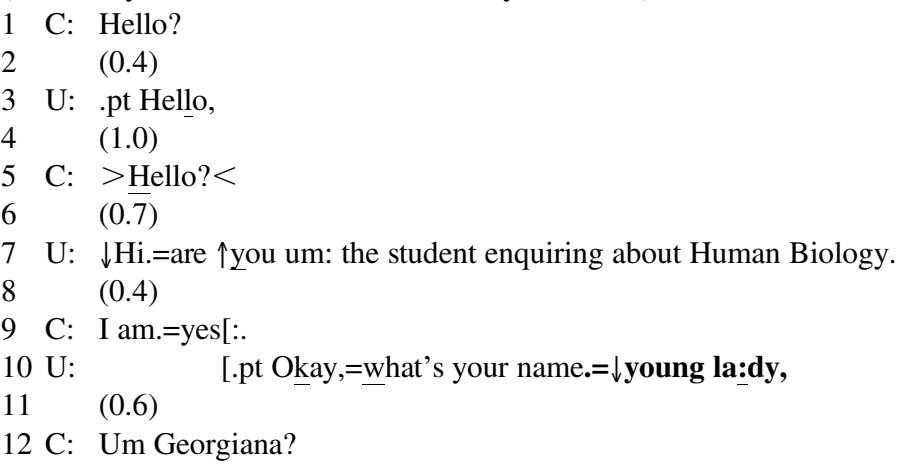

It seems that the main contact centre has supplied the departmental call-taker (U) with some information about the caller. This might account for U's 'try-marked' query about who their recipient is, at line 7 (Sacks \& Schegloff 1979). C confirms that they are "the student enquiring about Human Biology". Our analytic target is line 10 , in which $U$ explicitly orients to C's age, in a through-produced additional component to their question: "what's your name.= $\downarrow$ young la:dy,". While the gender category 'lady' may infer older age, prestige, or respectability (Stokoe 2011), the pairing with the word 'young' highlights C's (young) age as relevant; it also positions the call-taker as older than the caller. $\mathrm{C}$ does not orient to the categorization but simply responds to the main action of U's turn, providing her name.

Extract (5) is similar, in that the call-taker combines an age category with a gender category in the design of their question. Like in extract (4), the caller has been transferred to a different call-taker. 
(5) (University_211)

1 U: Is this thē: young gentleman who's- (0.) who's the

2 footballer,h

$3 \quad(0.3)$

4 C: No.

$5 \quad(0.5)$

6 U: $£$ Oka(h)yh $£$. .hh Js- $\downarrow$ Sorry.=Jus' remin' me again of your case.

$7 \quad=$ Which- which course is it y'wanted.

Like extract (4), U try-marks their question that, in this case, attempts to secure a footing for the subsequent interaction based on prior knowledge about the caller. In this case, U categorizes the caller as "thē: young gentleman", though C turns out not to be him.

In the university data, student callers typically did not orient to their age, while call-takers occasionally did so when addressing callers, as shown above. By contrast, in the holiday data, it was callers, not salespersons (S), who made age explicitly relevant, and this was primarily done in accounts. For example, in extract (6), the caller (C) invokes old age to account for being unable to remember her postcode.

(6) (Holiday_5; S: Salesperson, C: Caller)

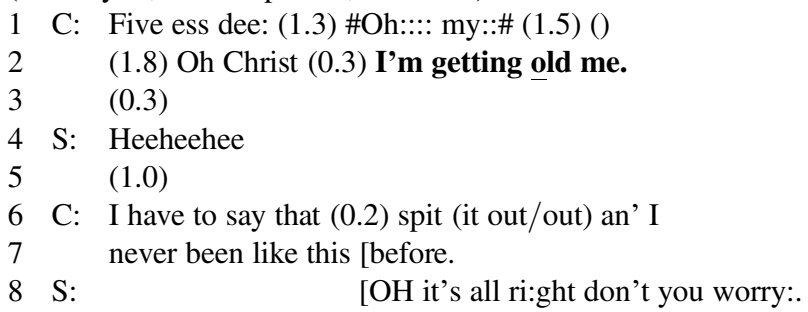

After failing to produce her full address, $\mathrm{C}$ supplies an account which includes the category-relevant description- "getting old" (line 2). In addition, she ties the category to a specific predicate: forgetfulness. Both parties treat this understanding of old age as requiring no further explanation, as $\mathrm{S}$ responds with laughter, not repair initiation. $\mathrm{S}$ thus displays an understanding of the account as humorous and/or selfdeprecating, and her laughter works to maintain social solidarity (cf. Holt 2012). In so doing, however, $\mathrm{S}$ does not add further topical, 'old-age' talk and returns the floor to $\mathrm{C}$ to provide their address. $\mathrm{C}$ instead pursues a more overt acknowledgement from S (cf. Pomerantz 1984), adding that she has "never been like this before" (line 7), thus supporting the claim that the problem is brought on by aging (and that she is not dispositionally a forgetful person). $\mathrm{S}$ responds by reassuring $\mathrm{C}$, treating the age-bound problem as understandable and unproblematic while discouraging further talk on the topic of forgetfulness and old age (cf. Flinkfeldt 2020).

In extract (7) age is similarly invoked to account for being unable to act as might be expected in a customer service setting. Here, $\mathrm{C}$ treats going online as the default 
way of progressing a holiday booking but is having difficulties using the system. This underpins her request for assistance over the phone.

(7) (Holiday_9)

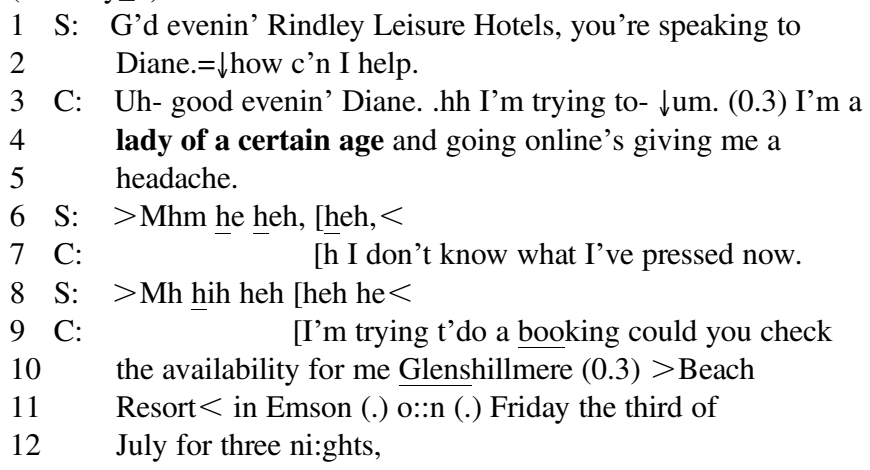

$\mathrm{C}$ introduces her reason for calling by stating that she is "trying" to do something. She temporarily abandons this turn and inserts an account for her failure, selfcategorizing as "a lady of a certain age" for whom going online incurs "a headache" (lines 4-5). Unlike the stereotypes implicit in the 'top down' segmenting of marketing, here we see how the customer uses a 'stereotypical' categorial inference (that older people are less technologically competent) as a resource to account for making telephone contact. Note the use of the indefinite article $a$, which generalizes the description and produces it as categorial (Edwards 2006). While $\mathrm{C}$ specifies age as particularly relevant to how her problem should be understood, the phrasing implies but does not spell out 'old', rendering C's self-categorization hearable as self-deprecating humour. Like in extract (6), S responds with affiliative laughter (lines 6, 8), which avoids overt agreement or disagreement with C's selfdeprecation (Holt 2012). This way, S acknowledges the category-bound issue but avoids topicalizing it, thereby avoiding further stereotyping and leaving $\mathrm{C}$ to drive the encounter forward. $\mathrm{C}$ returns to her earlier, abandoned reason for calling at line 9 ("I'm trying t'do a booking...").

This section has shown examples of how callers in the two datasets are constituted as members of a particular age category. There are some differences worth highlighting, beyond the broader relevance of age in these settings and the fact that the university corpus featured the category 'young' while the holiday corpus featured the category 'old'. While other-categorization occurred only in the university corpus, as fairly minimal address terms, self-categorization occurred only in the holiday corpus, with the clearest examples being part of accounts for failing to act as a 'proper' service user (e.g. knowing details and using the online booking system). Similarly, while being described as 'young' was treated as unproblematic (if responded to at all), categorizations as 'old' were responded to with reassurance and/or affiliative laughter. Beyond being relevant responses to accounts, such 
practices orient to aspects bound to old age as delicate and requiring some management, including forgetfulness or lack of tech skills. To the extent that old age categorizations may be understood as deprecating (in the sense that one may categorize oneself as old, but others - and perhaps especially customer service professionals — should not; cf. Pomerantz 1984), we would not expect professionals to acknowledge any age-based assumptions explicitly. This means that any systematic categorial basis for the way requests are designed would be expected to be tacit, implicit, or ambiguous (cf. Stivers \& Majid 2007; Whitehead 2020).

With the categorial analysis of this section in mind, we now move on to compare how each set of recipients are asked for the same information, an email address, in order to progress service provision.

\section{Comparing the design of email requests for different recipient groups}

In this section, we examine the formats of call-takers' requests for callers' email addresses. We start with instances from the university's admissions call-centre. In each of extracts (8)-(10), the call-taker's request presupposes that the caller has an email address and the caller confirms this by supplying it.

(8) (University_175)

1 U: .hhh O::kay, <A:nd if I can have you:r > email

2 address please.

$3 \quad(0.9)$

4 C: $>$ Okay $<$ uh:: < gee patel, $>$

(9) (University_87)

1 U: .hhh And what's your email address,

$2 \quad(0.5)$

3 C: .tch uh::m, .h s:uze:? anderson,

(10) (University_276)

$1 \mathrm{U}$ : And can I take: an email address,

2 (1.3)

3 C: Uh jurgen (.) dot krause, (0.2) ninety-six,

4 a:t geemail dot com.

Extracts (8)-(10) are just three examples of a practice that occurred in almost all of our 200 calls. Although there is some variation between the cases (which in itself indicates that these questions are not scripted), they share important features. To start with, all are and-prefaced, lending the questions a routine character (Heritage \& Sorjonen 1994). The requests also presuppose the existence of an email address: while the wH-question in extract (9) limits C's possibilities to deny having an email, the yes/no interrogatives in the other two examples ("can I have" and "can I take") only leave open whether the email will be provided, not whether $C$ has one. In each case, C's response is delivered with some turn-initial delay. While not the focus of 
our article, we understand the "uh"s (extracts (8) and (10)) and "uhm" (extract (9)) as a form of recipient design. That is, rather than indicate trouble in production, they work to prepare the call-taker for the upcoming, more complex piece of information.

In the holiday dataset, requests that presuppose that the caller has an email address only feature in cases where such details are apparently already in the system, such as in extract (11).

(11) (Holiday_24)

1 S: $>$ Lovely $<$.=And then I've got your email address:

2 uh::f gary white (0.2) five two one at bee tee

3 internet dot com.=Is that corre:ct, $=$

$4 \mathrm{C}$ : = That's right.

$5 \quad(0.3)$

$6 \mathrm{~S}:>$ Lovely $<=$

Here, S states that she has the customer's email, and formulates it so that $\mathrm{C}$ can confirm it. However, we found that having the email address already in the system' does not necessarily mean that it will be treated as unproblematic to use. In extract (12), for instance, $\mathrm{S}$ notices that the email address does not seem to fit the person she is speaking to. Age features at several points in the call, and immediately prior to the extract, $\mathrm{C}$ has informed $\mathrm{S}$ that she is older than her eighty-four-year-old sister.

(12) (Holiday_14)

1 S: Now uhm I've got an email address he:re, \#uh-\# (.)

2 Is this your email address?=

$3 \mathrm{C}:=$ No that must be my daughter's email add[ress. ]

$4 \mathrm{~S}:$

$5 \quad$ okay. So we'll take that out, okay $i$ 'Cause we

6 obviously want everything to come to you, .h So:

7 I'll just confirm for you then.

While $\mathrm{S}$ informs $\mathrm{C}$ that she has an email address on file, she goes on to check if it is in fact the caller's. The emphasis on "your" (line 2) singles out email ownership as the issue, rather than a problem with the address. Although the address has not been verbalized at this point, $\mathrm{C}$ quickly disconfirms ownership, aligning with the calltaker's displayed suspicion that the address is not C's and faciliating an understanding that $\mathrm{C}$ has no email address. $\mathrm{C}$ suggests that it "must be" her daughter's, thus displaying lack of knowledge about the email and adding a stage-of-life category that further makes relevant her age. In response, $S$ treats C's answer as indicating lack of email altogether, as she removes the address without asking for a replacement (and later informs $\mathrm{C}$ that the confirmation will be sent by post).

In the next set of extracts, all from the holiday dataset, we examine requests that do not presuppose that the caller has an email, and it is here that we see the marked contrast with how email addresses are solicited in the university dataset. 
(13) (Holiday_3)

1 S: Lovely. (.) Thank you: and uh do you have an email

2 address \#at all:\#.

3 C: No.

4 S: No that's ohkay,.HHh an: then finally just for some

5 security on your potential booking this evening

6 would it be alright to take a date of birth from

7 you mister Shaw:,

(14) (Holiday_6)

1 S: Five oh three, that is lo:vely, and uh do you have

2 an email address at all there,

3 C: Uh no [I don't.]

4 S: $\quad\left[{ }^{\circ} \mathrm{Mm}^{\circ}\right]$ That's okay. $>$ It's more trouble

5 than it's worth, [isn't it, $<$ ]

$6 \mathrm{C}:$ [ It is. ] [ heh heh. ]

$7 \mathrm{~S}: \quad$ [£That's no] problem.£

Like extracts (8)-(10), the email question is and-prefaced, appearing in a series of connected and routine questions. Although the polarity of the questions prefers a 'yes' response, they do not strongly presuppose that this will be supplied, as in the student calls. This is because the interrogatives in the holiday examples focus on whether or not $\mathrm{C}$ HAS an email, rather than whether or not it will be GIVEN. The 'do you have' construction functions like a pre-sequence to soliciting the caller's actual email (see Raymond 2010 on how shifts in grammatical format work to manage various contingencies). In addition, the extreme case formulations "\#at all:\#." and "at all there," (line 2 in both cases) enable a negative response by providing for the fact that $\mathrm{C}$ might not only be an irregular email user but might in fact have no experience whatsoever. This feature was absent in the university dataset.

C's immediate and type-conforming answers ("No." in extract (13), and "Uh no I don't." in extract (14)) treat the requests' presuppositions as appropriate (Raymond 2003). Notably, the callers do not orient to non-email use as accountable, whereas $\mathrm{S}$ in both cases works to reassure $\mathrm{C}$ that not having an email is unproblematic ("that's okay"; "It's more trouble than it's worth").

In cases where it turns out the customer does have an email address, callers often display difficulties in formulating it. This further distinguishes the email request sequences in the holiday corpus from the student calls, where email addresses were given with little trouble. In extract (15), C struggles to remember his email address.

(15) (Holiday_10)

1 S: \#Allright, lo:vely.\# $>$ And uh do you have an email

2 address at all, Mr Gree:n?

3 C: Uh:: I have yes it's uh: ${ }^{\circ}$ what is it uh. ${ }^{\circ}(0.3)$

4 paul, 


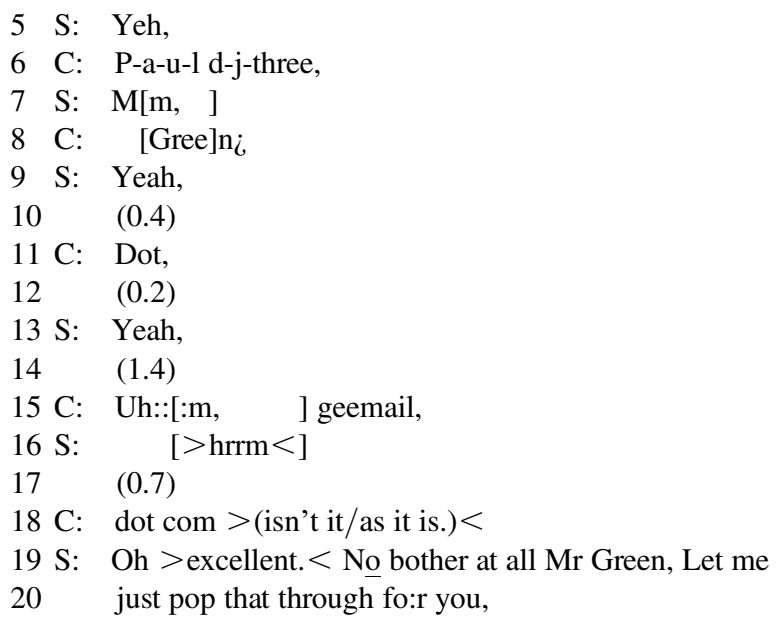

The design of S's request for C's email matches previous examples: it is an andprefaced interrogative with a polarity that prefers a 'yes' but is open to the possibility that there may not be one "at all". In line 3, $\mathrm{C}$ begins to provide his address. After the turn-initial "Uh::", C answers S's question: "I have yes". This illustrates a constraint the yes/no interrogative imposes on someone with an email to give, namely, to first answer the question, before providing the address. $\mathrm{C}$ begins to give the address ("it's uh:") but halts the production of his turn to 'ask himself' (note the lower volume) "what is it uh.", displaying unfamiliarity with it. In contrast to the turn-initial "uhs" that preface the production of student emails, C's "uhs" thus indicate trouble in providing the address. It is then produced stepwise, giving $\mathrm{S}$ the possibility to confirm each component and treating the email address - even such components as "dot" in line 11-as complicated and requiring extra care to communicate (cf. Svennevig 2018). After providing the final "dot com" component, C indicates further unfamiliarity with email, adding "isn't it" or "as it is". The first hearing "isn't it", suggests some uncertainty with providing the address, while the second hearing, "as it is", provides a largely redundant confirmation that "dot com" is the final component of an email address. This kind of stepwise production, over six turns, was not found in the student dataset.

The next extract shows a similar display of unfamiliarity with one's own email address.

(16) (Holiday_2; P: Partner)

$1 \mathrm{~S}$ : And do you have an email address that I can take?

2 C: Any?

3 S: EMAIL. (.) ADDRESS.

4 C: No:

5 S: No. Okay. In that case you:r (.) confirmation (1.0)

6 uh may get to you within- within ti:me, but I might 


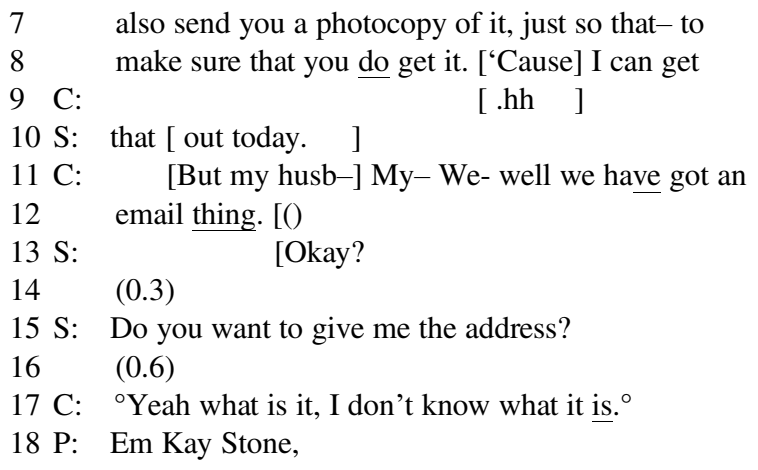

In response to S's request for an email, C initiates repair (“Any?”), which S treats as a problem of hearing (rather than understanding), repeating the requested item with increased volume and emphasis in line 3. Although reduced hearing can be understood as category-bound to old age, there is no mention of such a link. Once the requested item has been made clear, C's response ("No:.") is immediate and does not treat the non-use of email as accountable. $\mathrm{S}$ confirms C's response and proceeds to inform her that her booking confirmation should come "within ti:me"that is, it will be slower than if sent by email — and then proposes to send a photocopy so that $\mathrm{C}$ will receive a quicker confirmation, thus treating the lack of an email as problematic.

In overlap with S's proposal to get that "out today.", C changes her answer and wards off further reparative offers from S. With the contrastive "But my husb-" (in overlap, line 11), she starts attributing email ownership to her husband, and although she changes this to indicate shared use ("we"), there is no claim of individual ownership of the email (which may also account for previously denying having an email address, as it is not, in fact, hers). By referring to "an email thing." in lines 11-12, C further distances herself from the email. Unlike extract (15), C does not begin to give the address until $\mathrm{S}$ specifically requests it in line 15 . With the new information that $\mathrm{C}$ HAS an email address, the request can now focus on provision. The request, "Do you want to give me the address", orients to the relevance of stating the address when having one, and S's failure to do so. C's response in line 17 confirms that she wants to provide the address, but that she does not know what it is, again displaying being unfamiliar with the email despite it being presented as a joint account. Finally, in line 18, C's partner in the background, having listened to the call, starts to provide the address.

In this section, we have seen how requests for email addresses, and the expansions in sequences that they may initiate, are markedly different in the two datasets. While call-takers in the student calls design requests with the presupposition that the caller is an email user, in the holiday dataset the call-takers make no such assumptions about email use OR even internet access. Several factors may underpin the design of the requests in this respect. For the university dataset, prospective 
students will have given an email address at the point of applying; although calltakers do not have access to this, and cannot know if the email used is the student's own and is still active, it is a reasonable assumption that this fact informs the design of their requests for an email address. Similarly, for the holiday corpus, the fact that the customers call the service to make the booking in the first place (rather than going online), may inform call-takers' practice. Based on the established relevance of age in this environment, however, we suggest that this difference may also have to do with the callers' presumed age category; that is, that call-takers routinely design their requests at least in part based on the likely category memberships of their recipient (cf. Stivers \& Majid 2007; Wilkinson 2011). This understanding is supported by the analysis in the next section, where we show that, even when call-takers in the holiday dataset know that the caller uses email, they do not presume that this is their preferred mode of communication.

\section{Live construction of customer 'segments' via asking for preferences}

The final section examines the phase in which, in both datasets, it is established how confirmation (of the booking or offer) will be sent to the caller. We see that knowing that a recipient has an email may not be enough to assume that they will want to receive confirmation this way, and also how the desire or 'preference' of the caller - as formulated explicitly as such — is in this sense bound up with the preference (in CA terms) of offering confirmation. In the holiday dataset, despite the slowness of regular mail-by-post that is oriented to in extract (16), above, customers are typically given the possibility to 'opt in' to receive email confirmation. However, we start with an example, typical of all calls, from the university dataset.

(17) (University_206)

1 U: Kay eye enn gee,=And your surname;

2 (1.4)

3 C: Uh:m is ell ee ee.

4 (1.4)

5 U: Ell ee ee,=Thank you,=And an email addr[ess=

6 C:

$[\mathrm{Mm}$

$7 \mathrm{U}:=$ to contact you to send the: offer $_{i}$

$8 \quad(1.0)$

9 C: Uh:m is: d:ouble you ell kay.

U takes C's personal details and requests an email address "to send the: offer". Like in other student calls, the request format presupposes that the student has an email address. In addition, it is presumed that email is the preferred mode of contact and, unlike in the holiday calls, as we see shortly, no alternative is mentioned by either party.

In contrast, extract (18), from the holiday dataset, shows how even in cases where an email address is on file, it is not presumed to be the preferred way to receive a booking confirmation. 
(18) (Holiday_8)

1 S: .h Tha::t's it. > So what I'll do now for you, I'll

2 get your confirmation sent straight through. .hh

3 Now I have got your email address here, but would

4 you like it sent via the post instead? What would

5 be your preference?

6 C: Um- (0.3) will you: will you send it through the

7 post [actually,] [ because I ] will give

8 S: $\quad$ [.hh. $][>\uparrow$ Of course $<]$

9 C: Pauline her own $i$

$10 \mathrm{~S}$ : Oh of cou::rse.

In line 3, $\mathrm{S}$ informs $\mathrm{C}$ that she has her email address, but then offers to send the confirmation "via the post instead?". C is thus given an alternative despite being an email user and her choice is framed as a matter of "preference" (line 5), treating her as the kind of person-or, as belonging to an audience 'segment'-who might prefer post. In response, C indeed selects "send it through the post", while orienting to this as non-default (and possibly extra work for S) by adding "actually" in line 7 and supplying an account (that she will give a copy to her travel companion).

In extract (19), $\mathrm{C}$ has already received and read the confirmation email while the call is ongoing, but S still asks if she wants it in the post "as well".

(19) (Holiday_18)

1 S: Did you want it on- in the post as well or just

2 keep it to the email version.

$3 \quad(0.2)$

4 C: Uh:m (0.3) just leave it as an email version

5 [if you like,

6 S: [Yeah,

Here $\mathrm{C}$ is offered the option of postal confirmation IN ADDITION to the email already received. Again, this is formulated as a matter of preference-something $\mathrm{C}$ might "want", whereas the email version is treated as the simpler choice requiring no additional work. Correspondingly, when selecting email $\mathrm{C}$ does not formulate this as something she specifically wants, but that S can "leave it" if she "likes"-declining S's offer of postal confirmation is thus oriented to as a done for S's sake rather than C's. Extract (20) is similar.

(20) (Holiday_24)

1 S: Tha:t's $>$ lovely $<.=$ Would you like all paperwork to

2 come via email or through the post?

$3 \quad(0.9)$

4 C: Email will do.

5 (.) 
$6 \mathrm{~S}:>$ That's fine $<.=$ So that'll come pretty much instantly

7 for you.

Like previous examples, email is not treated as the mode for booking confirmations, despite there being an address on file that, in this case, $\mathrm{C}$ has confirmed in the beginning of the call (see extract (11)). Furthermore, while "paperwork" in the offer of email or post can be used for any type of files or written agreements, the etymology of the word means that it may be heard to indicate that a physical piece of paper would be expected. In this sense, the alternative interrogative is 'tilted' in favor of the postal option (cf. Llewellyn 2015). Although C opts for email, his choice is not phrased as a matter of preference, but as something that "will do", thus orienting to postal confirmation as the expected or better option. Additionally, S's explanation that the email confirmation will "come pretty much instantly" (lines 6-7), infers that $\mathrm{C}$ may have been heard not to be a regular email user, thus requiring a somewhat redundant explanation for someone accustomed to email use.

In the final example, $\mathrm{C}$ invokes old age as an account for the decision to buy travel insurance, binding aging to poor or deteriorating health. Following information related to the booking confirmation, $\mathrm{C}$ asks about how this will be sent to him. However, this turns out not to be a request for an email confirmation, but rather one to NOT get confirmation this way.

(21) (Holiday_23)

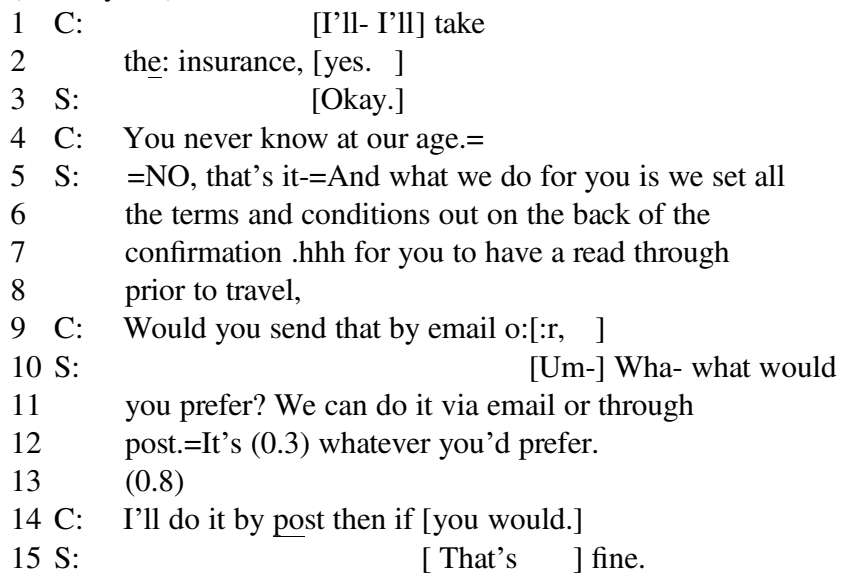

After agreeing with C's aged-based account for purchasing insurance, "you never know at our age", $\mathrm{S}$ informs $\mathrm{C}$ that the terms will be on the back of the booking confirmation. Similarly to "paperwork" in the previous extract, describing the information as being "on the back" implies a printed version sent by post (an email or pdf has no 'back'). This indicates some possibility that the confirmation will be sent by regular mail, even though early in the call it was established that $\mathrm{C}$ uses the internet and $\mathrm{S}$ confirmed his email address. At line 9, $\mathrm{C}$ asks if $\mathrm{S}$ would send the 
confirmation "by email o::r,", where "would" orients to institutional routines rather than makes a direct request. The alternative, by post, is not spelled out, but the trailoff "o::r," neutralizes the preference for email so that any answer may be framed as unproblematic from C's point of view (Stokoe 2010). In response, $S$ offers to send the confirmation either by email or through post depending on what $C$ prefers. This is in alignment with C's turn, as $\mathrm{S}$ does not treat $\mathrm{C}$ 's interrogative as a request for an email confirmation, but rather as a means of checking what the alternatives to the presumed method (email) might be.

In this section, then, we have identified a stark contrast in terms of practice. With the 'young' student callers in the university dataset, email is treated as mode of confirmation by default, with no deviations. But with older callers (and sometimes formulating them as such) who are contacting the holiday booking centre, the live segmentation of 'audiences' with different preferences is established through the provision of options for modes of communication for service confirmations. While offering alternatives, we see that the holiday call-takers construct offers in a way that makes it easier for callers to select 'post' over email. Unlike situations where a salesperson's turn design favours increased revenue (e.g. Llewellyn 2015), in our data, the holiday company has little to directly gain from facilitating this choice - indeed, a postal confirmation is likely more costly. In the longer term, the company of course has an interest in increasing their customers' satisfaction (and thereby potentially also revenues); by offering the option of postal confirmation, in the way that they do, salespersons treat this as something that might have such effects, that is, as something their customers might 'like'. These findingsalong with the stark difference to how the mode of communication was treated in the student calls - suggest that call-takers design their offers at least partly oriented to the customer's age category, that is, as belonging to a group who is more likely to prefer a physical letter rather than an email.

\section{I S C U S S I O N}

This article has investigated the possibility that a routine conversational practice in call-centre interaction might be designed differently, and initiate different kinds of sequences, in accordance with categorizations of the service user. Our analysis suggests that, in an environment where the interactants have no previous relationship, the professional may draw on whatever knowledge is available to them, including some category membership of the caller, as deduced from, for example, previous knowledge of the customer base, voice quality, or topical 'cues'. Specifically, the analysis shows how call-takers segment callers into 'parties that use/prefer email' and 'parties that don't use email or prefer regular mail'-partitionings which also match callers' presumed age categories. The (older) callers contacting a holiday sales center targeting seniors were asked WHETHER they had 'email AT ALL?', while the (younger) callers contacting a university were simply requested to provide their 'email address...?', thus displaying a presupposition that the 
student had one, whereas the senior holidaymaker might not. In the final part of the analysis we also found that callers' communication preferences, 'email' or 'post', were only solicited in the senior holiday calls, whereas in the student corpus, email was treated as the default option. The customers' presumed preference also underpinned the design of alternative interrogatives (email or post) and the 'preference' - in CA terms - built into those. These patterns also matched explicit mentions of age (being young/old) in the two datasets.

The callers in both datasets are, of course, categorizable in myriad ways. While 'student' is typically associated with (young) age, 'holidaymaker' or 'customer' is not readily associated with a particular age category (although the company in our data specifically targets seniors). What can we claim, then, about call-takers' possible categorizations of callers that are not formulated explicitly yet are a plausible account for at least some of the routinization of the practices we observed? There are many possible explanations for these differences, such as prior knowledge about typical customers being email users (in the case of students) or the fact that calling a service (in the holiday dataset) instead of using online options might in itself imply an infamiliarity with technology. While it is not possible to pin down exactly what informs service providers' choices in any particular instance, or what is most important for recipient design, the different ways by which emails are requested nevertheless treat, or constitute, recipients as having an email address or not. Even if a call-taker knows for sure that a caller has an email address, they can choose to request it in a way that DISPLAYs such a presupposition, or not. What we see is that in the university data displaying such a presupposition is treated as unproblematic, while in the holiday calls it is not. The match of these patterns to age groups, and the broader relevance of particularly old age in the holiday dataset, as shown in the first part of the analysis, thus provides for an understanding of the request formats as categorially based.

A persistent thread running through CA literature over several decades is a critique of approaches analyzing social interaction in terms of the a priori categorization of the speakers (e.g. because the speaker is old, a man, a doctor, French, and so on; classic papers include Schegloff 1997, Wetherell 1998, and Billig 1999, with subsequent development and commentary, e.g. Speer 1999, Stokoe 2000). This is because CA, unlike other 'qualitative' methods, aims to identify 'repetitive, uniform, typical and COHORT-INDEPENDENT' practices (Heap 1990:46, emphasis added). Conversation analysts have, therefore, been wrongfully criticized for being unable to deal with identity issues (especially tacit prejudice and discrimination) unless speakers explicitly make them relevant by mentioning them; in return, conversation analysts accuse those who claim the relevance of identity without endogenous evidence of 'theoretical imperialism' (Schegloff 1997; see Speer \& Stokoe 2011 for an overview of these debates).

Consequently, CA investigations of the interrelationship between membership categories and the systematic organization of talk have developed a focus on explicit invocations of categories used as resources for particular actions. While this can 
provide strong support for claims of categorial relevance (Stokoe 2012), it makes it difficult to explain patterns such as those observed in this article - although we have seen that age is treated as a relevant category in this setting, it is only occasionally made EXPLICITLY relevant in direct relation to the use of email and other technology. While this may make the claim of relevance less obvious, it makes it all the more important to find ways to explore the link between communicative action and categorization, as it is necessary that analysts 'deal not only with ALREADY FORMULATED descriptions of persons and activities... but with the occasion of the talk or other conduct itself' (Schegloff 2007b:473).

As Whitehead (2012:340) argues, working with larger collections can be a way to approach categorial phenomena that are not unambiguously formulated by speakers, as 'it may be possible to marshal as evidence other cases that share important features in common with the questionable case, while being somewhat more explicit with respect to participants' orientations to the categorial feature(s) of interest' (see also Whitehead 2020). This approach thus enables generalizable claims of how categories not only feature in — but permeate - talk and its design. As Stivers \& Majid (2007:435) argue, such applications of CA enable identification of conversational patterns as manifestations of implicit bias, and is an example of how micro-level interactions both reflect and contribute to larger macro-structural factors that combine to reproduce social... disparities'. Our analyses add to the findings of Nguyen (2011), Stivers \& Majid (2007), Wilkinson (2011), and Whitehead (2020) in suggesting the possibility of cohort DEPENDENT practices, in which actions are designed, and sequences unfold, according to cohorts (or categories, segments, or stereotypes). Unlike their studies, however, our findings rely on comparative analyses of two DIFFERENT datasets, opening up new possibilities for evidencing categorially based practices by larger-scale qualitative analysis.

The practices identified in this article can be considered alongside the marketing logic according to which an organization may identify the preferences of their customer base (Smith 1956). Indeed, we would argue that it is in moments such as these - in the unfolding 'live' practices by which customers are treated differently - that segments are GENERATED. In this respect, our approach is markedly different from the marketing literature discussed at the start of this article, in which static 'segments' or 'personas' are constructed a priori. We offer an alternative to the development of multiple and increasingly narrow segments in order to account for 'fleeting' identities or inconsistencies in customer behaviour: by employing an analysis of naturally occurring interaction, in which both parties interactively attribute or take into account categorization, we 'keep in mind that recipient design is also locally managed' (Nguyen 2011:200).

Service providers may, of course, have knowledge about their organization's processes that informs communicative conduct (e.g. that supplying an email address is a prerequisite for making a university application), as well as the experience of repeatedly encountering similar interactional situations (e.g. in which older holidaymakers do not always have an email address or may struggle using it if they 
do). This can facilitate the kind of routinely designed actions that we have examined in this article, but does not in itself mean these are not designed 'in the moment'. Rather, such instances can be seen as a form of routinized, yet 'live', segmentation of customers into 'types' (email non/users) that materializes in interaction with individual customers. Our analysis thereby highlights that recipient design is crucial for (and part of) providing good and effective service, so that 'doing recipient-design work is a part of being a competent professional' (Nguyen 2011:77). In addition, the analysis side-steps the problem of stereotypical segmenting (and the risk that it might backfire) by treating it not as a problem for the ANALYST, but for the PROFESSIONALS, which they need to-and observably Do-actively and constantly navigate in their encounters with clients.

\section{N O T E}

*We are grateful for the constructive feedback on earlier drafts of this article from two anonymous reviewers and the editorial team. This work was supported by the Swedish Research Council for Health, Working Life and Welfare (Forte 2018-01624 and 2017-01448).

\section{R E F E R E N C ES}

An, Jisun; Haewoon Kwak; Soon-gyo Jung; Joni Salminen; \& Bernard James Jansen (2018). Customer segmentation using online platforms: Isolating behavioral and demographic segments for persona creation via aggregated user data. Social Network Analysis and Mining 8(1), article 54. Online: https:// link.springer.com/article/10.1007\%2Fs13278-018-0531-0.

Baker, Carolyn; Michael Emmison; \& Alan Firth (2005). Calibrating for competence in calls to technical support. In Carolyn Baker, Michael Emmison, \& Alan Firth (eds.), Calling for help: Language and social interaction in telephone helplines, 39-62. Amsterdam: John Benjamins.

Bedi, Suneal (2019). Marketing's ethical blind spot: Catering to consumer preferences. Kelley School of Business Research Paper No. 19-50. Online: http://dx.doi.org/10.2139/ssrn.3441359.

Billig, Michael (1999). Whose terms? Whose ordinariness? Rhetoric and ideology in conversation analysis. Discourse \& Society 10(4):543-58.

Cirksena, Kathryn M., \& June A. Flora (1995). Audience segmentation in worksite health promotion: A procedure using social marketing concepts. Health Education Research 10(2):211-24.

Drew, Paul, \& John Heritage (1992). Analyzing talk at work: An introduction. In Paul Drew \& John Heritage (eds.), Talk at work: Interaction in institutional settings, 3-64. Cambridge: Cambridge University Press.

Edwards, Derek (2006). Facts, norms and dispositions: Practical uses of the modal verb would in police interrogations. Discourse Studies 8(4):475-501.

Enfield, Nick (2013). Reference in conversation. In Jack Sidnell \& Tanya Stivers (eds.), The handbook of conversation analysis, 433-54. Oxford: Wiley-Blackwell.

Firat, Fuat A., \& Clifford J. Shultz (1997). From segmentation to fragmentation: Markets and marketing strategy in the postmodern era. European Journal of Marketing 31(3/4):183-207.

Flinkfeldt, Marie (2020). Respecifying 'worry': Service and emotion in welfare encounters. Qualitative Research in Psychology 17(3):372-95.

Goodwin, Charles (1979). The interactive construction of a sentence in natural conversation. In George Psathas (ed.), Everyday language: Studies in ethnomethodology, 97-121. New York: Irvington.

Heap, James L. (1990). Applied ethnomethodology: Looking for the local rationality of reading activities. Human Studies 13:39-72. 
Heritage, John (2013). Action formation and its epistemic (and other) backgrounds. Discourse Studies 15(5):551-78.

— \& Maria-Leena Sorjonen (1994). Constituting and maintaining activities across sequences: And-prefacing as a feature of question design. Language in Society 23(1):1-29.

Hoey, Elliott M., \& Kobin H. Kendrick (2018). Conversation analysis. In Annette M. B. de Groot \& Peter Hagoort (eds.), Research methods in psycholinguistics: A practical guide, 151-73. Oxford: Wiley-Blackwell.

_ \& Elizabeth Stokoe (2018). Eligibility and bad news delivery: How call-takers reject applicants to university. Linguistics and Education 46:91-101.

Holt, Liz (2012). Using laugh responses to defuse complaints. Research on Language and Social Interaction 45(4):430-48.

Jansen, Bernard J.; Soon-gyo Jung; \& Joni Salminen (2019). Capturing the change in topical interests of personas over time. Proceedings of the Association for Information Science and Technology 56 (1):127-36.

Llewellyn, Nick (2015). Microstructures of economic action: Talk, interaction and the bottom line. The British Journal of Sociology 66(3):486-511.

McHoul, Alec (2007). 'Killers' and 'friendlies': Names can hurt me. Social Identities: Journal for the Study of Race, Nation and Culture 13(4):459-69.

Nguyen, Hanh T. (2011). Achieving recipient design longitudinally: Evidence from a pharmacy intern in patient consultations. In Joan Kelly Hall, John Hellermann, \& Simona Pekarek Doehler (eds.), L2 interactional competence and development, 173-205. Bristol: Multilingual Matters.

Parslow, Sophie (2018). 'Are you eligible for the flu jab?': Navigating eligibility and entitlement to GP-provided services.. Loughborough: Loughborough University MS thesis.

Pillet-Shore, Danielle (2012). Greeting: Displaying stance through prosodic recipient design. Research on Language and Social Interaction 45(4):375-98.

Pomerantz, Anita (1984). Agreeing and disagreeing with assessments: Some features of preferred/dispreferred turn shapes. In John Maxwell Atkinson \& John Heritage (eds.), Structures of social action: Studies in conversation analysis, 57-101. Cambridge: Cambridge University Press.

Pruitt, John, \& Tamara Adlin (2006). The persona lifecycle: Keeping people in mind throughout product design (interactive technologies). San Francisco, CA: Morgan Kaufmann.

Raymond, Geoffrey (2003). Grammar and social organization: Yes/no interrogatives and the structure of responding. American Sociological Review 68(6):939-67.

- (2010). Grammar and social relations: Alternative forms of yes/no-type initiating actions in health visitor interactions. In Alice F. Freed \& Susan Ehrlich (eds.), 'Why do you ask?': The function of questions in institutional discourse, 87-107. Oxford: Oxford University Press.

Sacks, Harvey (1972). On the analyzability of stories by children. In John J. Gumperz \& Dell Hymes (eds.), Directions in sociolinguistics: The ethnography of communication, 325-45. New York: Holt, Rinehart and Winston.

(1992). Lectures on conversation. Oxford: Blackwell.

, \& Emmanuel A. Schegloff (1979). Two preferences in the organization of reference to persons in conversation and their interaction. In George Psathas (ed.), Everyday language: Studies in ethnomethodology, 15-21. New York: Irvington.

- _ $\quad$ \& Gail Jefferson (1974). A simplest systematics for the organization of turn-taking for conversation. Language 50(4):696-735.

Schegloff, Emmanuel A. (1996). Some practices for referring to persons in talk-in-interaction: A partial sketch of a systematics. In Barbara Fox (ed.), Studies in anaphora, 437-85, Amsterdam: John Benjamins.

(1997). Whose text? Whose context? Discourse \& Society 8(2):165-87.

(2007a). Sequence organization in interaction: A primer in conversation. Cambridge: Cambridge University Press.

(2007b). A tutorial on membership categorization. Journal of Pragmatics 39(3):462-82.

Language in Society 51:4 (2022) 


\section{MARIE FLINKFELDT ET AL.}

Slater, Michael D. (1996). Theory and method in health audience segmentation. Journal of Health Communication 1:267-83.

Smith, Wendell R. (1956). Product differentiation and market segmentation as alternative marketing strategies. Journal of Marketing 21(1):3-8.

Speer, Susan A. (1999). Feminism and conversation analysis: An oxymoron? Feminism and Psychology 9(4):417-78.

, \& Elizabeth Stokoe (2011). An introduction to conversation and gender. In Susan A. Speer \& Elizabeth Stokoe (eds.), Conversation and gender, 1-28. Cambridge: Cambridge University Press.

Stivers, Tanya, \& Asifa Majid (2007). Questioning children: Interactional evidence of implicit bias in medical interviews. Social Psychology Quarterly 70(4):424-41.

Stokoe, Elizabeth (2000). Toward a conversation analytic approach to gender and discourse. Feminism \& Psychology 10(4):552-63.

(2010). 'Have you been married, or...?': Eliciting and accounting for relationship histories in speed-dating interaction. Research on Language and Social Interaction 43(3):260-82.

- (2011). 'Girl - woman - sorry!': On the repair and non-repair of consecutive gender categories. In Susan A. Speer \& Elizabeth Stokoe (eds.), Conversation and gender, 85-111. Cambridge: Cambridge University Press.

(2012). Moving forward with membership categorization analysis: Methods for systematic analysis. Discourse Studies 14(3):277-303.

Svennevig, Jan (2018). Decomposing turns to enhance understanding by L2 speakers. Research on Language and Social Interaction 51(4):398-416.

Wetherell, Margaret (1998). Positioning and interpretative repertoires: Conversation analysis and post-structuralism in dialogue. Discourse \& Society 9(3):431-56.

Whitehead, Kevin A. (2012). Moving forward by doing analysis. Discourse Studies 14(3):337-43.

(2020). The problem of context in the analysis of social action: The case of implicit whiteness in post-apartheid South Africa. Social Psychology Quarterly 83(3):294-313.

Wilkinson, Sue (2011). Gender, routinization and recipient design. In Susan A. Speer \& Elizabeth Stokoe (eds.), Conversation and gender, 112-34. Cambridge: Cambridge University Press.

(Received 22 July 2020; revision received 21 January 2021; accepted 4 February 2021; final revision received 7 February 2021)

Address for correspondence:

Marie Flinkfeldt

Centre for Social Work (CESAR)

Department of Sociology

Uppsala University

Box 624, 75126 Uppsala, Sweden

Marie.Flinkfeldt@soc.uu.se 